\title{
ÂNCORA NEBULOSA DA FORMAÇÃO INICIAL DE PROFESSORES PARA A INFÂNCIA: COMO ENFRENTAREMOS?
}

\author{
ÁNGASE NEBULOSA DE LA FORMACIÓN INICIAL DE PROFESORES PARA LA \\ INFANCIA: ¿CÓMO ENFRENTAREMOS?
}

\author{
NEBULAUS ANCHOR OF THE INITIAL TRAINING OF TEACHERS FOR \\ CHILDHOOD: HOW WILL WE FACE IT?
}

\author{
Heloisa Toshie Irie SAITO ${ }^{1}$ \\ Marta Regina Furlan de OLIVEIRA ${ }^{2}$ \\ Solange Franci Raimundo YAEGASHI ${ }^{3}$
}

RESUMO: O intuito deste texto é analisar a formação inicial de professores para a educação infantil no contexto brasileiro atual, estudando especificamente o processo formativo no Curso de Pedagogia de duas universidades estaduais públicas do estado do Paraná. Essa análise é primordial nos contextos social e educacional vigentes, caracterizados por vários retrocessos e por baixos investimentos governamentais. A metodologia é um estudo bibliográfico na modalidade de análise documental, tomando por base o método histórico e a análise de disciplinas específicas voltadas à formação inicial para o trabalho na educação infantil do Curso de Pedagogia das Universidades Estaduais de Londrina e de Maringá, ambas localizadas no Paraná. Os resultados direcionam para a possibilidade emancipatória da formação inicial docente, com fundamentos teórico-metodológicos críticos e humanizadores do ensino.

PALAVRAS-CHAVE: Formação de professores. Educação infantil. Universidades públicas.

RESUMEN: El objetivo principal del texto es analizar la formación inicial de profesores de la educación infantil en el contexto actual, con una mirada específica al proceso formativo en el Curso de Pedagogía de dos Universidades Estatales Públicas del Estado de Paraná. Se pretende, además, reflexionar sobre la formación de calidad de los profesores de la infancia para el enfrentamiento de los desafios que se presentan en el contexto social y educativo vigente. La metodología es un estudio bibliográfico en la modalidad de análisis documental, tomando como base el método histórico y, análisis de las disciplinas específicas dirigidas a la formación inicial para la educación infantil del Curso de Pedagogía de las Universidades Estaduales de Londrina y de Maringá, del Estado de Paraná. Los resultados dirigen hacia la

\footnotetext{
${ }^{1}$ Universidade Estadual de Maringá (UEM), Maringá - PR - Brasil. Professora do Departamento de Teoria e Prática da Educação e do Programa de Pós-Graduação em Educação. Doutora em Educação (USP). ORCID: https://orcid.org/0000-0003-1061-5933. E-mail: htisaito@uem.br

${ }^{2}$ Universidade Estadual de Londrina (UEL), Londrina - PR - Brasil. Professora do Departamento de Educação e do Programa de Pós-Graduação em Educação. Doutora em Educação (UEM). ORCID: https://orcid.org/00000003-2146-2557. E-mail: marta.furlan@yahoo.com.br

${ }^{3}$ Universidade Estadual de Maringá (UEM), Maringá - PR - Brasil. Professora do Departamento de Teoria e Prática da Educação e do Programa de Pós-Graduação em Educação. Doutora em Educação (UNICAMP). ORCID: https://orcid.org/0000-0002-7666-7253. E-mail: solangefry@gmail.com
} 
posibilidad emancipatoria de la formación inicial docente, con fundamentos teóricometodológicos críticos y humanizadores de la enseñanza.

PALABRAS CLAVE: Formación de profesores. Educación infantil. Universidades públicas.

ABSTRACT: The main objective of the text is to analyze the initial formation of teachers of children's education in the current context, with a specific look at the training process in the Pedagogy Course of two Public State Universities of the State of Paraná. It is also intended to reflect on the quality training of the teachers of the childhood to face the challenges that present themselves in the current social and educational context. The methodology is a bibliographic study in the form of documentary analysis, based on the historical method and analysis of the specific disciplines focused on the initial education for children 's education of the Pedagogy Course of the State Universities of Londrina and Maringá, Paraná State. The results point to the emancipatory possibility of initial teacher training, with theoretical and methodological fundamentals critical and humanizing teachers.

KEYWORDS: Teacher training. Child education. Public universities.

\section{Primeiras palavras}

Dos pontos de vista histórico e legal, as iniciativas de formação inicial de professores vêm sofrendo mudanças significativas, principalmente, da década de 1980 até os dias atuais. Até meados da década de 1980, a legislação brasileira era omissa quanto à educação da criança pequena, apresentando uma política governamental que desqualificava a área e, por consequência, os seus profissionais.

Verificamos que na década de 1980 houve um movimento de reformulação e avanços em relação à educação no país. Saviani (2009, p. 148) ressalta que, a partir desses movimentos, "a maioria das instituições tendeu a situar como atribuição dos cursos de Pedagogia a formação de professores para a Educação Infantil e para as séries iniciais do ensino de $1^{\circ}$ grau"; como consequência, promulgou-se, em 1996, a LDB, lei n. 9.394, que determina, em seu artigo 62, que a formação de professores para a educação básica se daria em nível superior, "admitida, como formação mínima para o exercício do magistério na Educação Infantil e nos cinco primeiros anos do Ensino Fundamental, a oferecida em nível Médio, na modalidade Normal” (BRASIL, 1996).

Desde então, a educação infantil e a formação de professores para a infância passaram a ser historicamente mais pesquisadas, discutidas e reivindicadas, iniciando um movimento crítico em prol de mudanças na educação para as crianças de 0 a 6 anos e, consequentemente, exprimindo novas exigências de formação ao profissional que atua com essa faixa etária. Isso 
possibilitou repensar o trabalho pedagógico voltado às crianças pequenas com vistas ao processo de emancipação no que se refere ao cuidado e à educação delas. Nesse sentido, as políticas públicas relacionadas ao trabalho na educação infantil ${ }^{4}$ têm ampliado suas ações e discussões em relação à criança, à sua infância e ao atendimento educacional, pretendendo uma educação de mais qualidade. Há, todavia, muito a avançar no que tange à formação inicial e à atuação dos profissionais envolvidos nessa etapa educacional (NASCIMENTO; LIRA, 2017; SCHEIBE, 2007).

Diante disso, o presente texto tem como objetivo principal analisar a formação inicial de professores para a educação infantil no contexto atual, com um olhar específico para o processo formativo no Curso de Pedagogia de duas universidades estaduais públicas do estado do Paraná. Mesmo que haja uma vasta contribuição com textos científicos e com obras sobre esse assunto, acreditamos que a âncora inconsciente e nebulosa da formação de professores da infância ainda está presente atualmente, necessitando, desse modo, de um novo enfrentamento do olhar (concepções) e da ação (prática docente) em direção à formação emancipatória do ensino.

Para tanto, compreender a história do processo formativo docente permite a reflexão acerca da formação docente no contexto atual, bem como a compreensão dos ranços e dos avanços no trabalho com a infância. Por isso, é importante pensar na formação inicial do professor da infância, considerando os marcos legais e históricos como provocadores, desde a década de 1980, de novos olhares e de novos direcionamentos educativos para com a primeira infância, pensando sobre os enfrentamentos necessários nos campos formativo e pedagógico (NASCIMENTO; LIRA, 2017). A Carta Constitucional de 1988 é um desses marcos; a partir dela, a criança passou a ser vista como sujeito de direito que precisa ser respeitado na sua individualidade e na sua especificidade, como um ser histórico e cultural que constrói e reconstrói a história social mediante as relações humanas que estabelece ao seu redor (BRASIL, 1998). De acordo com Drumond (2008), concomitante ao novo modo de olhar para a criança legislativamente, enfatizou-se a discussão acerca da identidade do profissional da educação infantil, assim como novos horizontes pedagógicos que devem permear as formações inicial e continuada desse profissional.

Como metodologia de trabalho, optamos pela pesquisa bibliográfica na modalidade de análise documental, tomando por base o método histórico e a análise das disciplinas do Curso de Pedagogia das Universidades Estaduais de Londrina e de Maringá, ambas no Paraná,

\footnotetext{
${ }^{4}$ A expressão educação infantil foi adotada recentemente no Brasil, a partir das disposições expressas na Constituição de 1988, assim como na Lei de Diretrizes e Bases da Educação Nacional de 1996, as quais contribuíram para o processo de educação como direito para as crianças pequenas.
} 
voltadas à formação inicial para a educação infantil. Para o estudo, utilizam-se os fundamentos críticos da educação, a fim de potencializar um olhar desmistificador em relação a esse processo formativo docente, em busca de sua especificidade profissional na posição de professor responsável pela primeira etapa da educação básica.

Didaticamente, o texto está organizado da seguinte forma: no primeiro momento, fazemos um panorama histórico da formação inicial de professores para a educação infantil, pautando-nos na legislação brasileira, a partir de 1988. Em seguida, analisamos o Curso de Pedagogia, tomando como base as Diretrizes Curriculares Nacionais para a Educação Infantil de 2009 para o trabalho com as crianças de 0 a 6 anos, objetivando observar e pontuar as contribuições e os conteúdos das disciplinas destinadas à formação inicial para a educação infantil contidas na grade curricular do Curso de Pedagogia da Universidade Estadual de Londrina (UEL) e da Universidade Estadual de Maringá (UEM). Para finalizar, levantamos alguns apontamentos necessários para pensarmos em uma formação inicial de qualidade dos professores à luz das contribuições das universidades públicas, a fim de desmistificar a relação cuidar e educar, atribuindo significados mais amplos, caracterizando os processos de aprendizagem das áreas desenvolvidas e apresentadas cotidianamente às crianças.

Hoje, no Brasil, o grande desafio dos cursos que formam professores é graduar um profissional qualificado. Considerando esse desafio, as reflexões aqui apresentadas poderão incitar debates, em âmbitos acadêmico e educacional, a fim de ampliar os horizontes pedagógicos docentes com vistas às intencionalidades educativas, ao papel responsável do ensino na aprendizagem de crianças e ao compromisso com a formação humanizadora dos sujeitos infantis.

Defendemos que o professor da educação infantil precisa ter os fundamentos teóricometodológicos para que possa possibilitar a aprendizagem das crianças por meio do processo de intervenção sistematizada, ou seja, possibilitar, pelo ensino e pela mediação dos conteúdos, a aprendizagem da criança, no sentido de ampliar suas leituras de mundo, suas ações, suas experiências e suas manifestações culturais, em amplos aspectos da vida humana (PASCHOAL et al., 2016; SAITO; OLIVEIRA, 2018; SARMENTO; FOSSATTI, 2012; SILVA; BITTENCOURT; OLIVEIRA, 2019; YAEGASHI, BIANCHINI; PIRES, 2018).

\section{Formação de professores para a educação infantil: trajetória e expectativas}


Quando se desvaloriza a história por ela se ocupar do que já passou, o risco está na ilusão de se inventar a roda novamente (KUHLMANN JÚNIOR, 2004, p. 6, grifo do autor).

O tema formação de professores da educação infantil é, atualmente, alvo de grandes discussões no cenário brasileiro e de grandes impasses também. Dos pontos de vista histórico e legal, há uma luta significativa no sentido de ressignificar o trabalho docente mediante uma formação inicial qualificada. Segundo Saviani (2009), a discussão em torno da formação docente já fora preconizada por Comenius, no século XVIII, mas, somente no século XIX essa questão exigiu uma resposta institucional. Como consequência, foram criadas as Escolas Normais como instituições encarregadas de prepararem professores para o exercício do magistério.

Em se tratando do Brasil, a necessidade da formação docente emerge, de forma explícita, após a independência do país, com a organização da instrução popular, assim denominada na época. Desse contexto em diante, a trajetória histórica da formação de professores no Brasil assumiu uma conotação significativa, fortalecendo as discussões, principalmente ao longo dos últimos dois séculos: XX e XXI (SAVIANI, 2009).

No que se refere à formação de professores para a educação infantil, o caminho histórico trilhado não é diferente, já que é fruto das discussões, das mudanças históricas de atendimento à criança, dos direitos e dos objetivos educacionais desse nível de ensino, bem como da necessidade de se buscar um trabalho pedagógico qualificado para as crianças desde a mais tenra idade.

No que diz respeito ao direito à educação, tanto na Constituição Federal de 1988 quanto nas Leis de Diretrizes e Bases da Educação (LDB), n. ${ }^{\circ}$ 4.024/1961 e n. ${ }^{\circ}$ 5.692/1971, verificamos a obrigatoriedade somente para crianças a partir dos 7 anos de idade e, de modo pontual, para as crianças menores desta faixa etária ficaram assinaladas ínfimas iniciativas, como estimular as empresas a organizarem instituições educativas e afirmar a necessidade de receberem educação conveniente. Devido a isso, o atendimento às crianças de 0 a 6 anos oriundas das classes populares ficou, em grande parte, ao encargo dos órgãos públicos de assistência social que, com a finalidade de "cuidar", visavam possibilitar às mães o acesso ao mercado de trabalho. Nesse contexto social, as creches, como instituições assistenciais, atendiam crianças de 0 a 2 anos ou mais. $\mathrm{O}$ atendimento educacional às crianças acontecia a partir de 3 anos, com as chamadas classes de pré-escola instituídas nas escolas primárias, nas de $1^{\circ}$ grau ou nas de ensino fundamental, e estava sujeito sempre ao número de vagas ofertadas, em geral, muito inferior à demanda (PAULINO; CÔCO, 2016). 
Assim, a educação infantil e, de modo particular, a creche, foi concebida historicamente como serviço assistencial, priorizando os cuidados da criança, não havendo necessidade de um profissional preparado e/ou formado. Essa concepção de atendimento perdurou durante muitos anos e, consequentemente, desencadeou descrédito ao professor de crianças, que por vezes esteve associado a um sentimento romantizado em relação ao seu trabalho pedagógico na creche, ou seja, a função do profissional da infância estava associada ao sentimento de "amor" pelas crianças (ARCE, 2001).

Arce reforça que isso se dá pelo fato de que, historicamente, foi definida "a imagem do profissional dessa área como sendo da mulher naturalmente educadora, passiva, paciente, amorosa, que sabe agir com bom senso, é guiada pelo coração, em detrimento da formação profissional” (ARCE, 2001, p. 167). Há, ainda, outros fatores, como a desvalorização salarial, a inferioridade perante os demais professores atuantes em outros níveis e em outras modalidades de ensino e a associação do trabalho docente ao trabalho doméstico e à maternagem.

A partir da LDB n. ${ }^{\circ}$ 9.394/1996, conhecida como Lei de Diretrizes e Bases da Educação Nacional (LDBEN), ficou demarcada a garantia de "atendimento gratuito em creches e pré-escolas às crianças de zero a seis anos de idade”. No entanto, a mudança mais significativa para a educação infantil está inscrita no Capítulo I, "Da composição dos Níveis Escolares", mais especificamente no artigo 21, inciso I, o qual estabelece que "A educação escolar compõe-se de: educação básica, formada pela educação infantil, ensino fundamental e ensino médio" (BRASIL, 1996).

Coadunando com esse direcionamento legal, tivemos a publicação da Resolução CNE/ CP n ${ }^{\circ}$, de 2006, instituindo as Diretrizes Curriculares Nacionais para o Curso de Graduação em Pedagogia, e, na sequência, as orientações dispostas nas Diretrizes Curriculares Nacionais para a Educação Infantil (DCNEI) de 2010, enfatizando os eixos das interações e brincadeiras assim como os princípios éticos, políticos e estéticos como fundantes na organização da prática pedagógica. A partir de todo este compilado de legislações e diretrizes, conseguimos verificar o surgimento de algumas mudanças no modo de compreender e propor um trabalho com as crianças, incidindo também na maneira de estruturar a formação dos professores para essa faixa etária, interferindo assim no processo de construção da identidade dos profissionais docentes que atuam com a primeira infância $(0 \text { a } 6 \text { anos })^{5}$.

\footnotetext{
${ }^{5}$ Neste momento, a primeira infância ainda era considerada de 0 a 6 anos. Esse cenário só será alterado, em
} 2006, com a Lei n. ${ }^{\circ} 11.274 / 06$, conhecida como Lei dos Nove Anos. 
Além disso, a expansão quantitativa de creches e de pré-escolas desde a década de 1970 no Brasil provocou a necessidade de acompanhamento do trabalho educativo qualitativo e da ampliação de estudos relacionados ao trabalho pedagógico do docente no cotidiano da educação infantil. Isso posto, a formação de professores para a educação infantil tornou-se um dos objetivos a ser alcançado no intuito de garantir esse "novo olhar" para o processo de atendimento educacional das crianças, principalmente no que se refere à ressignificação e à revisão das práticas pedagógicas de atendimento (KUHLMANN JÚNIOR, 2004).

Kramer (2005) afirma que, antes da década de 1970, as políticas educacionais propunham compensar carências culturais e afetivo-sociais, deficiências linguísticas ou defasagens afetivas. Mesmo diante de equívocos referentes à proposta compensatória, não se pode desconsiderar o seu papel na década de 1970, já que impulsionou o debate sobre as funções e as ações pedagógicas no trabalho com crianças pequenas.

Aos poucos, foi surgindo a necessidade de se perceber a criança como sujeito de direitos, que merece uma educação digna, coerente e condizente com suas reais necessidades e com suas potencialidades de aprendizagem. Paschoal e Brandão (2015) afirmam que as formas de atendimento educacional às crianças têm avançado de maneira significativa em relação à legislação e às políticas públicas voltadas à educação infantil no Brasil.

No entanto, os "pacotes" de decretos e de leis não são suficientes para a efetivação de um trabalho de qualidade com as crianças pequenas. Se, no passado, o amor, os afetos e os cuidados com a saúde e com a higiene bastavam para garantir a educação das crianças, na atualidade defendemos que há a necessidade de uma formação profissional teórico-prática para que seja possível a mediação do conhecimento em prol da aprendizagem e do desenvolvimento integral das crianças pequenas.

Cerisara (2002) chama-nos atenção ao fato de que as mudanças relacionadas ao trabalho pedagógico na educação infantil não são naturais, mas sim historicamente construídas, já que ocorreram a partir de vários movimentos em que foram defendidas a criança e a necessidade de formação de qualidade dos profissionais educacionais responsáveis por essa faixa etária. Essas mudanças sofreram grandes interferências, considerando as macrossociais e aquelas observadas na instituição familiar, por exemplo, com a inserção da mulher no mundo do trabalho.

No que se refere ao atendimento educacional, Silva, Paschoal e Oliveira (2013) reconhecem, nesse processo, a presença maciça de mulheres na profissão do magistério pelo fato da sociedade considerar que a figura feminina seria a mais apropriada para atuar com a criança pequena, ou seja, "as mulheres seriam mais afetivas a essas virtudes e, portanto, a elas 
caberia muito a função de professoras polivalentes" (BRASIL, 1999, p. 30). Na realidade, permeou-se uma representação de trabalho docente destinado às crianças, cujos requisitos são muito mais a sensibilidade, a paciência e o aspecto materno do que a formação e o preparo profissional docente. Traçar o perfil dos profissionais da educação infantil significa, portanto, considerar, entre outros fatores, a formação inicial de professores para garantir uma atuação emancipada desse profissional que esteja voltada ao trabalho pedagógico de ensino, de aprendizagem e de desenvolvimento das crianças.

Ainda, vale frisar que, mediante as transformações nesse cenário, podemos perceber que, atualmente, a atuação masculina nessa etapa de ensino tem acontecido de maneira ampla. Assim, para além dos desígnios femininos, as percepções profissionais na primeira infância definem-se, também, como masculinas, com o conceito atual de "gênero", que implica uma referência às origens sociais das identidades subjetivas dos homens e das mulheres (AMÂNCIO, 2003). Essa identidade de gênero é uma construção progressiva de imagens de masculinidade ou de feminilidade ligada aos papeis sociais a serem desempenhados em determinada sociedade. Desse modo, nesse processo histórico de mudanças no trabalho pedagógico na educação infantil, não há como negar a presença e a inserção do gênero masculino na categoria profissional de educador de infância, mesmo que, tradicionalmente, esse espaço "pertença" ao mundo feminino (GONÇALVES; OLIVEIRA, 2018; JAEGER; JACQUES, 2017; MONTEIRO; ALTMANN, 2014).

Desse modo, a formação de professores se constitui por buscas individuais e coletivas que atingem as dimensões pessoal, institucional, sindical, cultural e que se relacionam com a dinâmica do conhecimento científico e dos saberes construídos ao longo do exercício profissional. Assim, os saberes da docência não são formados por uma vertente única, mas por um processo complexo de iniciativas em favor da formação com mais qualidade. A exigência, na atualidade, é priorizar a integração entre cuidados e educação e a construção de conhecimentos e de aprendizagens da criança pequena, sendo este o grande desafio para a educação infantil.

No contexto atual emergente, o que se espera do profissional da infância é um trabalho pedagógico que contemple cuidado e educação de maneira indissociável, sendo que ele deve desenvolver essa relação no sentido de promover conhecimento e aprendizagem nas crianças. De acordo com Saito e Tacahashi (2019, p. 303), “a verdade é que cuidar e educar estão intimamente imbricados, isto é, quando uma criança é cuidada, ela também é educada. Isso ocorre nas situações mais corriqueiras, como: no ato de escovar os dentes, no momento da alimentação, na hora do banho, na troca de fraldas [...]". Os ranços, porém, são visíveis no 
cotidiano do trabalho com as crianças, pois, em alguns casos, vemos claramente a fragmentação do trabalho, representado, de um lado, pela professora que educa e, do outro lado, pelos atendentes e pelos auxiliares que cuidam. É necessário, portanto, refletir sobre essa situação, a fim de analisar as fragilidades que essa forma de organização tem proporcionado ao processo de educação, com vistas a um atendimento educacional de qualidade, considerando, ainda, que as diferentes funções e a hierarquização, com carga horária e com disparidade salarial, geram desconfortos e conflitos.

Quanto mais o trabalho pedagógico está voltado à criança pequena, menor é o prestígio do profissional da educação. Tal compreensão encontra-se no interior dos espaços educativos e, principalmente, no ideário da própria sociedade, estendendo-se também aos cursos de formação inicial e continuada de professores.

Por esse motivo, é importante voltarmos o nosso olhar aos cursos de formação de professores para compreendermos de que modo a organização desses cursos incide no desenvolvimento das práticas pedagógicas. Assim, para termos um parâmetro da configuração da formação inicial para professores da educação infantil, em especial no estado do Paraná, na sequência, trazemos a estrutura curricular de dois Cursos de Pedagogia de duas universidades estaduais paranaenses no intuito de analisar as disciplinas especificamente voltadas à educação infantil, bem como os conhecimentos proporcionados por tais composições formativas.

\section{Currículo do Curso de Pedagogia de duas universidades públicas paranaenses: possíveis contribuições para o enfrentamento na formação inicial docente}

De acordo com a LDB em vigência, em seu artigo 61, a formação profissional docente deve "atender aos objetivos dos diferentes níveis e modalidades de ensino e às características de cada fase de desenvolvimento do educando", tendo como fundamento "a associação entre teorias e práticas, inclusive mediante a capacitação em serviço", atrelada ao "aproveitamento da formação e experiências anteriores" (BRASIL, 1996), as quais são adquiridas em instituições formativas de ensino (universidades) e em outras atividades que não do ensino.

Nesse sentido, a formação inicial do docente para a educação infantil deverá contemplar, em seu currículo, saberes específicos relativos a essa etapa educacional, estabelecidos a partir das Diretrizes Curriculares Nacionais para o curso de Pedagogia, de modo a contemplar a necessidade de articulação entre o cuidar e o educar nas diferentes práticas pedagógicas, evitando ações fragmentadas, mecânicas e descontextualizadas. Para 
tanto, cabe a necessidade de uma proposta curricular de formação inicial docente que garanta tais especificidades no trabalho com as crianças.

Entendemos aqui ser necessário destacar que para pensar sobre a formação inicial de professores, é necessário refletir acerca da postura político-social e pedagógica dos professores formadores do Curso de Pedagogia no intuito de se elaborar um espaço aberto para as discussões e para as análises em torno dos aspectos específicos da profissionalização docente, uma vez que, segundo Formosinho (2002, p. 41), "o seu desenvolvimento profissional reflete necessariamente o seu tipo de profissionalidade".

Para analisar que tipo de desenvolvimento profissional está sendo propiciado nos cursos de Pedagogia e, em especial, nas duas universidades públicas paranaenses, apresentaremos a estrutura curricular do curso de Pedagogia da UEL e da UEM objetivando refletir sobre o processo formativo docente, tecendo um olhar crítico para as potencialidades e para as fragilidades no campo da formação do profissional que atuará na educação infantil. Podemos dizer que os dois cursos estão estruturados de forma a oferecer as disciplinas de formação geral e específica sem habilitação, atendendo, portanto, as Diretrizes Curriculares Nacionais para o Curso de Graduação em Pedagogia.

O objetivo do Curso de Licenciatura em Pedagogia da UEL é a formação de professores para exercer funções de docência no magistério na educação infantil e nos anos iniciais do ensino fundamental, no magistério das matérias pedagógicas do ensino médio, de gestão pedagógica e em áreas nas quais sejam previstos conhecimentos pedagógicos. $\mathrm{O}$ curso destina-se, dessa forma, tanto à formação inicial docente quanto à formação de gestores educacionais, compreendendo a participação desse profissional na organização e na gestão de sistemas e de instituições de ensino com as seguintes ações didático-pedagógicas: planejamento, execução, coordenação, acompanhamento e avaliação de tarefas próprias do setor da educação, bem como planejamento, execução, coordenação, acompanhamento e avaliação de projetos e de experiências educativas não escolares.

O Projeto Pedagógico do Curso de Pedagogia da UEL foi implantado em 2010, estando em vigor até então. Foi elaborado com base em três grandes áreas: docência, gestão pedagógica e pesquisa. A organização do currículo é disciplinar e seriada, de modo a garantir uma gama de conhecimentos necessários para as três grandes áreas citadas. Como disciplinas voltadas às práticas de ensino, temos o Estágio Curricular obrigatório que está alocado na $3^{\mathrm{a}}$, na $4^{\mathrm{a}}$ e na $5^{\mathrm{a}}$ séries do curso. Na $3^{\mathrm{a}}$ série temos o estágio supervisionado na educação infantil; na $4^{\mathrm{a}}$ série o estágio supervisionado nas séries iniciais e na gestão no espaço escolar; na $5^{\mathrm{a}}$ 
série o estágio supervisionado em espaços não escolares (UNIVERSIDADE ESTADUAL DE LONDRINA, 2010).

Em se tratando das disciplinas especificamente voltadas ao trabalho pedagógico infantil, na $2^{\mathrm{a}}$ série do curso são ofertadas duas disciplinas: "Educação Infantil" (72 horas) e "Organização do Trabalho Pedagógico" (72 horas). Na 3ª́rie do curso, temos as disciplinas "Saberes e Fazeres na Educação Infantil" (72 horas) e "Práticas Educativas no Berçário" (72 horas). Além dessas, temos as disciplinas "Estágio Supervisionado em Educação Infantil", com 100 horas/aula, e "Trabalho de Conclusão de Curso" (TCC) em que os alunos podem optar por pesquisas relacionadas à área de educação infantil e que está alocada na $3^{\mathrm{a}}$, na $4^{\mathrm{a}} \mathrm{e}$ na $5^{\mathrm{a}}$ séries, com as atividades de TCC 1 , de TCC 2 e de TCC 3. Além disso, o graduando tem a oportunidade de participar de atividades acadêmicas complementares por meio das seguintes ações: a) participação em projetos de ensino, pesquisa e extensão e integrados; b) estágio curricular não obrigatório; c) participação em congressos, seminários, simpósios, colóquios, mesas redondas; d) audiências de defesas de dissertação ou de tese; e) trabalhos de iniciação científica; f) monitorias; g) apresentação de trabalhos em eventos científicos; h) representação estudantil; i) programas de extensão e de formação complementar no ensino de graduação; j) disciplinas especiais; k) cursos de extensão; 1) disciplinas eletivas oferecidas pela UEL; m) participação em eventos científicos, culturais e/ou artísticos, mediante comprovação; n) disciplinas vinculadas à área, cursadas em outras IES, não incluídas no histórico escolar da UEL (UNIVERSIDADE ESTADUAL DE LONDRINA, 2010).

Desse modo, no que diz respeito aos conteúdos oferecidos nas diferentes áreas, os acadêmicos têm contato com um conjunto de conhecimentos gerais na $1^{\mathrm{a}}$ e na $2^{\mathrm{a}}$ séries do curso. A partir da $2^{\mathrm{a}}$ série, eles já recebem conteúdos relacionados à formação inicial para a educação infantil, os quais se estendem nos anos seguintes do curso, por meio da prática de estágio supervisionado na educação infantil e do trabalho de conclusão de curso.

Se observarmos as disciplinas ofertadas para a formação do professor infantil em sintonia com a grade curricular do curso e com a sua carga horária, de início, verificamos como essa área, timidamente reconhecida no Curso de Pedagogia da UEL, é frágil e fragmentada quando se trata da formação inicial para a educação infantil. Diante disso, se não houver interlocução entre as disciplinas, além de a formação ser reduzida, corre-se o risco de cometer os equívocos pedagógicos com repetições de conteúdo e/ou a fragmentação do ensino.

Além disso, mesmo com todos os esforços do corpo docente dessa área, há a visível percepção de que as discussões em torno das disciplinas não garantem a formação de 
qualidade dos acadêmicos, principalmente pela própria redução da carga horária destinada às quatro disciplinas específicas e ao conjunto de conteúdos que deve ser trabalhado em sala de aula.

Outro problema é a falta de um conjunto de conhecimentos, tais como: a infância e a cultura, a ludicidade, as linguagens da criança e os campos de experiência, a diversidade e a inclusão na educação infantil, a arte e a educação em amplos aspectos; eles acabam sendo oferecidos de modo superficial, considerando que há a ementa específica das disciplinas e o tempo encurtado do ensino no curso. Sobre essa questão, é importante considerar que esses conhecimentos devem ser trabalhados no curso à luz dos pressupostos teórico-metodológicos críticos do conhecimento, distanciando-se, completamente, de um receituário didático ou pedagógico.

Além disso, se observarmos o currículo do Curso de Pedagogia da UEL com a ideia que temos atualmente sobre o conceito de currículo como caminhada, trajetória, direção e processo de produção de determinados conhecimentos, a situação causa preocupação, por considerarmos que os ranços são visíveis no próprio curso de formação inicial, quando trata a educação infantil e o profissional dessa etapa com um olhar de desprestígio docente.

O Curso de Licenciatura em Pedagogia da UEM, por sua vez, possui três ênfases: a construção da identidade profissional, a docência e a formação de gestor de processos educativos, sendo ministrado nas modalidades presencial e semipresencial. Objetiva formar um profissional que seja capaz de conhecer e de analisar o mundo em que vive, de modo a vincular as questões educativas e as questões sociais mais amplas, almejando a efetividade das ações pedagógicas. Para isso, a organização curricular é feita com base em dois ciclos formativos: o ciclo de formação inicial integrada, que é composto por eixos integradores, em torno dos quais se articula toda a base para a formação de educadores, e os ciclos de formação continuada para a qualificação profissional por meio de cursos de extensão, de atualização e de especializações. Vale a pena ressaltar que, mesmo estando em consonância com as Diretrizes Curriculares Nacionais para o Curso de Graduação em Pedagogia de 2006, o Curso de Pedagogia da UEM estava em processo de reformulação no período de elaboração desse artigo, tendo em vista as novas exigências nacionais para as licenciaturas (UNIVERSIDADE ESTADUAL DE MARINGÁ, 2005), passando a funcionar com o novo currículo no ano de 2020 .

Considerando a estrutura que estava em vigência, apresentamos, a seguir, a organização referente às disciplinas voltadas à educação infantil. No $2 .^{\circ}$ ano do curso, são seis disciplinas assim divididas: no primeiro semestre, "Fundamentos Filosóficos da Educação 
Infantil" (34h), "Formação e Ação Docente: Prática de Ensino em Educação Infantil I" (34h) e "Estágio Curricular Supervisionado de Educação Infantil I" (68h); já no segundo semestre, "História da Infância no Brasil” (34h), "Formação e Ação Docente: Prática de Ensino em Educação Infantil II" (34h) e "Estágio Curricular Supervisionado de Educação Infantil II" (34h). No 3..$^{\circ}$ ano, são ofertadas duas disciplinas no primeiro semestre: "Formação e Ação Docente: Prática de Ensino em Educação Infantil III" (34h) e "Estágio Curricular Supervisionado de Educação Infantil III" (68h). Sendo assim, temos o total de 340h em um universo de $3.840 \mathrm{~h}$ de curso, ou seja, menos de $10 \%$ de carga horária destinada às disciplinas relativas à educação infantil.

Em termos quantitativos, consideramos uma carga horária muito baixa para desenvolver com os acadêmicos as compreensões necessárias à prática educativa com as crianças dessa faixa etária, de modo a contemplar todas as especificidades do desenvolvimento infantil e do trabalho pedagógico na creche e na pré-escola. Além disso, no Curso de Pedagogia da UEM, assim como no da UEL, ainda é frágil e fragmentada a ação que se refere à formação inicial para a educação infantil.

Kishimoto (2002), ao discutir sobre o currículo dos cursos de formação de professores no Brasil, comenta que a maneira como eles são estruturados não contribui com o futuro docente. Esse fato se justifica porque ainda há lacunas na compreensão dos egressos desses cursos em relação ao que é necessário ensinar à criança pequena e como essa aprende e se desenvolve, principalmente por considerar que a grade curricular dos cursos é fragmentada e apresenta conteúdos por meio de disciplinas compartimentadas, que não dialogam entre si.

A formação profissional no interior das universidades tem reproduzido práticas em que os professores se organizam em campos disciplinares, criam-se tradições, feudos e priorizam determinados campos de conhecimento em detrimento de outros: em uns, saberes históricos e filosóficos, sociológicos e antropológicos ou organizacionais entre outros (KISHIMOTO, 2002, p. 108).

Sendo assim, há que se criar uma cultura do coletivo e não do individual, a fim de que os professores das diferentes disciplinas consigam dialogar e formar um egresso em Pedagogia que consiga atuar com maestria na docência e, em especial, na docência na educação infantil. Se ousamos lutar por uma educação de qualidade nos espaços formativos para a educação infantil, então, há a necessidade de iniciarmos esse processo de valorização e de experiência formativa de qualidade desde a formação inicial do docente. Nesse sentido, defendemos a necessidade de um currículo que permita formar profissionais para além do sentimento de amor e de paixão por crianças; eles precisam ter condições dignas e 
fundamentadas no conhecimento, a fim de garantirem uma educação emancipatória para as nossas crianças pequenas.

Em busca de novos direcionamentos formativos, entendemos que olhar para a especificidade dos currículos do Curso de Pedagogia da UEL e da UEM permite-nos pensar sobre o currículo do Curso de Pedagogia de um modo geral, assim como também amplia nossa reflexão acerca do que é necessário para uma atuação docente emancipadora e de qualidade. Insistimos que devemos lutar por uma ampliação da carga horária voltada à docência na educação infantil dentro do curso de formação inicial de professores, bem como por uma articulação entre as diferentes disciplinas curriculares.

Também defendemos que existem outras possibilidades para além do currículo obrigatório, as quais podem ser possíveis saídas. Assim, os projetos de ensino, de pesquisa, de extensão e os grupos de estudos que são desenvolvidos em ambas as universidades em torno da formação de professores para a educação infantil podem ser direcionadores de olhares para o trabalho específico com a infância, por meio de propostas atualizadas e ampliadas nos fundamentos e nas discussões relacionadas às políticas públicas para o trabalho formativo na educação infantil. Tais atividades caracterizam-se por espaços formativos e de estudo que direcionam o olhar, de modo mais específico, à temática, permitindo a análise e o aprofundamento teórico. Por sua vez, os projetos e os cursos de extensão contribuem significativamente para o processo de ampliação do trabalho docente na educação infantil, quando são feitas formações para alunos do Curso de Pedagogia e para a comunidade externa em atuação nas instituições educativas. Assim, tanto a formação inicial quanto a continuada, quando bem estruturadas e conduzidas, podem contribuir para um trabalho educativo de qualidade com as crianças pequenas. Desse modo, o currículo do Curso de Pedagogia precisa pensar a formação não no sentido técnico, tampouco instrumentalizado por uma perspectiva parcial e reducionista, mas sim considerando quem é o sujeito e como levá-lo a refletir acerca de suas possibilidades de apropriação de conhecimentos.

\section{Palavras finais}

A discussão sobre a formação inicial de professores para a educação infantil traz à tona a necessidade de ponderarmos a dimensão educacional nas referidas instituições de atendimento à criança pequena, considerando um conjunto necessário de conhecimentos e de aprendizagens para o processo formativo docente. Nesse prisma, o trabalho formativo inicial 
nas universidades públicas, nosso objeto de estudo, assume um movimento epistêmico e dialético, entremeado por conflitos, em prol da garantia de tal função educativa e de cuidados, o que, por si, acaba sendo um grande paradoxo na formação docente.

O desafio, nesse sentido, é avançar em direção a uma proposta que atenda às especificidades do trabalho com crianças de 0 a 6 anos de idade em sintonia com as mudanças atuais emergentes dirigidas a essa etapa da educação básica. Para tanto, o conjunto de saberes escolares disposto pelas disciplinas no currículo do Curso de Pedagogia das universidades precisa garantir essa interlocução entre teoria e prática, com elaborações epistêmicas fundamentadas pelos pressupostos teórico-metodológicos de educação para essa faixa etária do ensino.

Kramer (2005) aponta para novos olhares em relação a esse processo formativo inicial docente, com o intuito de contribuir para a discussão acerca do trabalho pedagógico com as crianças, considerando a urgência de se ter "[...] novos paradigmas, reinventando o trabalho nas creches e pré-escolas, recriando rotinas, dando leveza ao cotidiano de crianças e adultos que partilham essas instituições [...] dando visibilidade à criança a partir de suas formas de expressar e significar o mundo (KRAMER, 2005, p. 215).

Esse processo é infinito quando nos comprometemos a refletir criticamente sobre a prática pedagógica do ensino e consideramos a necessidade de ressignificarmos o currículo de formação inicial docente. É preciso garantir ao profissional da educação infantil um conjunto de conhecimentos que the permita atuar, visando a qualidade do ensino, por meio de intervenções pedagógicas condizentes com as necessidades e com as especificidades infantis. Nesse processo, consideramos necessário e relevante que o docente desenvolva as facetas de pesquisador, de investigador e de transformador da realidade.

Assim, a formação oferecida pelas universidades deve estar amparada nos fundamentos críticos educacionais do ensino, para que não se permita, pelo conjunto de saberes escolares docentes, a desvalorização da tradição em detrimento do prestígio exacerbado do novo, isto é, das tais "inovações curriculares" no que se refere à formação de professores, a fim de enterrarmos o "velho" - conhecimentos historicamente construídos como saber formativo em desuso. O desafio está na reinvenção ou na ressignificação do currículo para formação inicial do docente de modo a garantir uma gama de conhecimentos que lhe permita assumir a posição de autoridade pedagógica do ensino em espaços formativos para a educação infantil.

Sendo assim, defendemos que a universidade tem um papel importante e insubstituível no processo formativo inicial docente, uma vez que possibilita a constituição do pensamento 
autônomo e investigativo envolvido pela concepção e pela contextualização do ensino, já que "só a universidade tem um investimento constitutivo na produção de conhecimento e na análise crítica da realidade e da sociedade" (FORMOSINHO, 2002, p. 170).

Ainda, se ressignificado o currículo de formação inicial, pode-se pensar em garantir o trabalho profissional docente com vistas ao aprendizado crítico de conteúdos variados. Nessa perspectiva, é necessária uma formação inicial mais abrangente que valorize os conhecimentos já acumulados no exercício profissional ao longo da história da educação infantil.

Reiteramos que discutir sobre a formação inicial de professores para a educação infantil requer compreender o quão desafiador e complexo é esse processo, pois envolve direcionamentos e diretrizes nacionais, estruturas curriculares, relações de poder e uma herança histórica de assistencialismo que precisa ser ressignificada. Por isso, a universidade, em especial, a pública, é um espaço importante para que ocorra essa reflexão no sentido de garantir uma formação inicial docente que contemple as especificidades de um trabalho pedagógico voltado às crianças de 0 a 5 anos de idade. Nesse sentido, reconhecemos o papel ativo do Curso de Pedagogia das duas universidades em discussão, mas defendemos que há muito a ser alterado para que o currículo de ambas permita um aprofundamento dos conhecimentos específicos relacionados a essa faixa etária e, consequentemente, um fazer docente mais consciente e elaborado.

Para isso, podemos pensar em uma formação inicial emancipatória do estudante do Curso de Pedagogia, a fim de que, pelo processo de ensino, de pesquisa e de extensão, ele possa apropriar-se das discussões relacionadas ao trabalho com as crianças da educação infantil, além de vivenciar situações enriquecedoras do cotidiano formativo com as experiências advindas do estágio supervisionado curricular e do não curricular que compõem o Curso de Pedagogia. Em suma, a nossa defesa é que, desde a formação inicial, possamos garantir uma atuação docente coerente e condizente com as necessidades das crianças no campo do conhecimento e da aprendizagem.

\section{REFERÊNCIAS}

AMÂNCIO, L. O Gênero no discurso das Ciências Sociais. Análise Social, v. 168, p. 687$714,2003$.

ARCE, A. Documentação oficial e o mito da educadora nata na educação infantil. Cadernos de pesquisa, n. 113, p. 167-184, 2001. Disponível em: http://www.scielo.br/pdf/cp/n113/a09n113.pdf. Acesso em: 14 mar. 2020. 
BRASIL. Constituição da República Federativa do Brasil. Brasília, DF: Senado Federal, 1988.

BRASIL. Lei n. 4.024, de 20 de dezembro de 1961. Fixa as Diretrizes e Bases da Educação Nacional. Brasília, DF, 27 dez. 1961. Disponível em:

https://www2.camara.leg.br/legin/fed/lei/1960-1969/lei-4024-20-dezembro-1961-353722normaatualizada-pl.pdf. Acesso em: 14 mar. 2020.

BRASIL. Lei n. 5.692, de 11 de agosto de 1971. Fixa as Diretrizes e Bases para o ensino de $1^{\circ}$ e $2^{\circ}$ graus e dá outras providências. Diário Oficial da União, Brasília, DF, 12 ago. 1971. Disponível em: https:/www2.camara.leg.br/legin/fed/lei/1970-1979/lei-5692-11-agosto1971-357752-norma-pl.html. Acesso em: 14 mar. 2020.

BRASIL. Lei n. 9.394, de 20 de dezembro de 1996. Estabelece as Diretrizes e Bases da Educação Nacional. Diário Oficial da União, Brasília, DF, 23 dez. 1996. Disponível em: http://www.planalto.gov.br/ccivil_03/leis/19394.htm. Acesso em: 19 mar. 2020.

BRASIL. Ministério da Educação e do Desporto. Secretaria de Educação Fundamental. Referenciais para a formação de professores. Brasília, DF: MEC/SEF, 1999.

CERISARA, A. B. Professoras de Educação Infantil: entre o feminino e o profissional. São Paulo: Cortez, 2002.

BRASIL. Lei n. 11.274, 6 de fevereiro de 2006. Dispõe sobre a duração de 9 (nove) anos para o ensino fundamental, com matrícula obrigatória a partir dos 6 (seis) anos de idade. Diário Oficial da União, Brasília, DF, 7 fev. 2006. Disponível em: http://www.planalto.gov.br/ccivil_03/_Ato2004-2006/2006/Lei/L11274.htm. Acesso em: 19 mar. 2020.

BRASIL. Resolução CNE/CP n. 1, de 15 de maio de 2006. Institui as Diretrizes Curriculares Nacionais para o Curso de Graduação em Pedagogia, Licenciatura. Diário Oficial da União, Brasília, DF, 16 maio 2006. Disponível em:

http://portal.mec.gov.br/cne/arquivos/pdf/rcp01_06.pdf. Acesso em: 14 mar. 2020.

BRASIL. Ministério da Educação. Secretaria de Educação Básica. Diretrizes curriculares nacionais para a educação infantil / Secretaria de Educação Básica. Brasília, DF: MEC/ SEB, 2010. Disponível em:

http://portal.mec.gov.br/dmdocuments/diretrizescurriculares_2012.pdf. Acesso em: 04 dez. 2020.

DRUMOND, V. Formação de professoras e professores de Educação Infantil: por uma Pedagogia da Infância. Zero-a-seis, v. 20, n. 38, p. 288-301, 2018. Disponível em: https://doi.org/10.5007/1980-4512.2018v20n38p288. Acesso em: 14 mar. 2020.

FORMOSINHO, J. A universidade e a formação de educadores de infância: potencialidades e dilemas. In: MACHADO, M. L. A. (Coord.). Encontros e desencontros em educação infantil. São Paulo: Cortez, 2002. p. 169-188. 
GONÇALVES, J. P.; OLIVEIRA, E. L. Diversidade cultural e relações de gênero em uma escola indígena sul-mato-grossense. Educação e Pesquisa, v. 44, e185144, p. 1-19, 2018. Disponível em: https://www.scielo.br/j/ep/a/W4bz7dfNGWqRLyKsp9brBXG/?lang=pt. Acesso em: 14 mar. 2020.

JAEGER, A. A.; JACQUES, K. Masculinidades e docência na educação infantil. Revista Estudos Feministas, v. 25, n. 2, p. 545-570, 2017. Disponível em:

https://www.scielo.br/j/ref/a/M9qfpLxghJxZPF7qxKDG59n/?lang=pt. Acesso em: 14 mar. 2013.

KISHIMOTO, T. M. Avanços e retrocessos na formação dos profissionais de educação infantil. In: MACHADO, M. L. A. (Coord.). Encontros e desencontros em educação infantil. São Paulo: Cortez, 2002. p. 107-115.

KRAMER, S. Profissionais de educação infantil: gestão e formação. São Paulo: Ática, 2005 .

KUHLMANN JÚNIOR, M. Infância e educação infantil: uma abordagem histórica. Porto Alegre: Mediação, 2004.

MONTEIRO, M. K.; ALTMANN, H. Homens na educação infantil: olhares de suspeita e tentativas de segregação. Cadernos de Pesquisa, v. 44, n. 153, p. 720-741, 2014. Disponível em: https://www.scielo.br/j/cp/a/RLTGrW43VVJqGZPpr3Qdk5p/?lang=pt. Acesso em: 14 mar. 2020.

NASCIMENTO, S. M. B.; LIRA, A. C. M. Marcos legais para a formação de professores da educação infantil e desafios à docência. Zero-a-seis, v. 19, n. 35, p. 99-116, 2017. Disponível em: https://periodicos.ufsc.br/index.php/zeroseis/article/view/1980-4512.2017v19n35p99. Acesso em: 14 mar. 2020.

PASCHOAL, J. D. et al. A educação infantil em foco: desafios e perspectivas para a educação dos bebês. Revista Ibero-Americana de Estudos em Educação, Araraquara, v. 11, n. 4, p. 2174-2190, 2016. Disponível em:

https://periodicos.fclar.unesp.br/iberoamericana/article/view/8530/6052. Acesso em: 14 mar. 2020 .

PASCHOAL, J. D.; BRANDÃO, C. F. A contribuição da legislação para a organização do trabalho pedagógico na educação infantil brasileira. Revista HISTEDBR On-Line, v. 15, n. 66, p. 196-210, 2015. Disponível em:

https://periodicos.sbu.unicamp.br/ojs/index.php/histedbr/article/view/8643710. Acesso em: 14 mar. 2020.

PAULINO, V. B. R.; CÔCO, V. Políticas públicas educacionais: vozes que emergem no trabalho docente na Educação Infantil. Ensaio: Avaliação e Políticas Públicas em Educação, v. 24, n. 92, p. 697-718, 2016. Disponível em: https://www.scielo.br/j/ensaio/a/wzfqYF8Y9VN7NWXFkZRFLBj/?lang=pt. Acesso em: 14 mar. 2020. 
SAITO, H. T. I.; OLIVEIRA, M. R. F. Trabalho docente na educação infantil: olhares reflexivos para a ação intencional e planejada do ensino. Imagens da Educação, v. 8, n. 1, e39210, 2018.

SAITO, H. T. I.; TACAHASHI, A. S. M. A imaginação e a educação infantil: uma relação necessária e possível. In: OLIVEIRA, M. R. F. (Coord.). Indústria cultural, educação e trabalho docente: da semiformação à emancipação humana. Londrina: UEL, 2019. p. 301315.

SARMENTO, D. F.; FOSSATTI, P. Formação de professores, saberes docentes e práticas educativas: a qualidade da educação infantil como centralidade. Revista Portuguesa de Educação, v. 25, n. 2, p. 117-140, 2012. Disponível em: http://www.scielo.mec.pt/scielo.php? script=sci_arttext\&pid=S0871-91872012000200006\&lng=pt\&tlng=pt. Acesso em: 14 mar. 2020 .

SAVIANI, D. Formação de professores: aspectos históricos e teóricos do problema no contexto brasileiro. Revista Brasileira de Educação, v. 14, n. 40, p. 143-155, 2009. Disponível em: https://www.scielo.br/j/rbedu/a/45rkkPghMMjMv3DBX3mTBHm/?lang=pt. Acesso em: 14 mar. 2020.

SCHEIBE, L. Diretrizes curriculares para o curso de pedagogia: trajetória longa e inconclusa. Cadernos de Pesquisa, v. 37, n. 130, p. 43-62, 2007. Disponível em: https://www.scielo.br/j/ cp/a/cCY6yjvfhYPKWNbFMMmL3Pm/?lang=pt. Acesso em: 14 mar. 2020.

SILVA, A. T. T.; BITTENCOURT, C. A. C.; OLIVEIRA, M. R. F. A experiência da infância entre os dilemas da educação moderna e o empobrecimento do trabalho docente. Revista Ibero-Americana de Estudos em Educação, Araraquara, v. 14, esp. 4, p. 2032-2045, 2019. Disponível em: https://periodicos.fclar.unesp.br/iberoamericana/article/view/12926/8695. Acesso em: 14 mar. 2020.

SILVA, A. T. T.; PASCHOAL, J. D.; OLIVEIRA, M. R. F. A percepção dos acadêmicos do Curso de Pedagogia sobre a formação do professor de Educação Infantil. In: JORNADA DE DIDÁTICA, 2.; SEMINÁRIO DE PESQUISA DO CEMAD: DOCÊNCIA NA EDUCAÇÃO SUPERIOR: CAMINHOS PARA UMA PRÁXIS TRANSFORMADORAS, 1., 2013, Londrina. Anais [...] Londrina, PR: UEL, 2013. p. 72-82. Disponível em: http://www.uel.br/eventos/jornadadidatica/pages/arquivos/II\%20Jornada\%20de $\% 20$ Didatica $\% 20 \mathrm{e} \% 20 \mathrm{I} \% 20$ Seminario $\% 20 \mathrm{de} \% 20$ Pesquisa $\% 20 \mathrm{do} \% 20 \mathrm{CEMAD} \% 20-\% 20$ Docencia $\% 20$ na $\% 20$ educacao $\% 20$ Superior $\% 20$ caminhos $\% 20$ para $\% 20$ uma $\% 20$ praxis $\% 20$ transformadora/A \%20PERCEPCAO\%20DOS\%20ACADEMICOS\%20DO\%20CURSO\%20DE \%20PEDAGOGIA.pdf. Acesso em: 14 mar. 2020.

UNIVERSIDADE ESTADUAL DE LONDRINA. Projeto Pedagógico do Curso de Licenciatura em Pedagogia da Universidade Estadual de Londrina. Londrina, PR: UEL, 2010 .

UNIVERSidAde estadual DE MARINGÁ. Projeto Pedagógico do Curso de Licenciatura em Pedagogia da Universidade Estadual de Maringá. Maringá, PR: UEM, 2005. 
YAEGASHI, S. F. R.; BIANCHINI, L. G. B.; PIRES, J. G. C. Representações sociais de acadêmicos de pedagogia sobre o estágio supervisionado em educação infantil. Conhecimento \& Diversidade, v. 10, n. 20, p. 26-37, 2018. Disponível em: https://revistas.unilasalle.edu.br/index.php/conhecimento_diversidade/article/view/3549. Acesso em: 14 mar. 2020.

\section{Como referenciar este artigo}

SAITO, H. T. I.; OLIVEIRA, M. R. F.; YAEGASHI, S. F. R. Âncora nebulosa da formação inicial de professores para a infância: como enfrentaremos? Revista Ibero-Americana de Estudos em Educação, Araraquara, v. 16, n. 3, p. 2047-2066, jul./set. 2021. e-ISSN: 19825587. DOI: https://doi.org/10.21723/riaee.v16i3.13467

Submetido em: 19/03/2020

Revisões requeridas em: 03/12/2020

Aprovado em: 05/01/2021

Publicado em: 01/07/2021 